human agency, are so abundant in the same place, nevertheless the fact of a similar association occurring far in the interior affords strong presumptive evidence on this point, as the finely-finished implements must have been carried inland and to the same spots where the Moa remains occur, to be used at native feasts, of which these bones are the only other existing evidences.

So far I have been dealing with evidence gathered in the South Island of New Zealand of the recent co-existence of Man and the Moa, but in the North Island there is no lack of similar proofs. During the summer of I 866, H.E. Sir George Grey, K.C.B., made a fine collection at Waingongoro on the west coast of this island, being the same locality from which Mantell gathered the magnificent series of bones which he forwarded to Europe in 1847 . At this place, along with the bones of the Moa and other extinct birds, were found those of dogs, seals, and many species of birds that are common at the present day, such as the albatross, penguin, nestor, and porphyris, and notably the notornis, a gigantic rail, which till a comparatively recent date, was supposed, like the Moa, to be extinct, and of which as yet only two living examples have been obtained. Associated with these remains Sir George Grey obtained artificially formed stone flakes of a very peculiar kind, being chips from rolled boulders of hard crystalline sandstone, produced by a single blow, probably when the stone was heated and quenched in water. The stones from which these chips were obtained had evidently been used, in the first instance, for cooking, as the ancient Umus, or cooking-ovens, are chiefly formed of them ; and, indeed, in the sandy tracts on the west coast, where stones are rare, the identical stones that in former days were used for cooking Moas are still in use by the natives of the district for ccoling pigs and shell-fish. Here again we find that the same necessity and circumstance which suggested the use of the chert flakes in the South, gave origin to a similar adaptation of the chips from the sandstone boulders. It is of some interest to find that native tradition points to the sandy flat at Waingongora, called Te Rangatapu, as the spot where the first Maori inmigrants to the district originally settled; and there appears to be nothing in the abundant traces which they have left of these great feasts, which we must refer to that period, that would indicate any difference in their domestic habits from those of the Maoris now existing, and who, no doubt, are their direct descendants.

What has been advanced affords strong presumptive evidence that the Moas, although belonging probably to a race that was expiring from natural causes, was finally exterminated through human agency; and on this subject Mr. Murison has suggested how infallibly the wholesale consumption of the eggs, which were evidently highly prized as an article of food, must have led to their rapid extinction, without its being necessary that the birds themselves should have been actually destroyed. That wide-spreading fires contributed, in some instances, to the destruction of these wingless birds, is rendered probable from the occurrence of little heaps of bones, in spots where flocks of them would be overtaken when fleeing before the destroying element. At the south-west extremity of a triangular plain, by the side of the Wakatipu Lake, in 1862, I counted thirty-seven of such distinct skeletonheaps, where the steep rocky slope of the mountain, covered with fallen blocks and tangled shrubs, meets the lake, and would, therefore, stop the progress of the fugitives in that direction. From what we know of habits of birds akin to the Moas, we may fairly infer that they did not frequent heavily-timbered country, but roamed over coppice-covered plains and mountain slopes. This view is supported by the comparative rarity of Moa remains in forests, the few exceptions being easily accounted for.

The whole of the eastern district of the South Island of New Zealand back to the Southern Alps was completely surveyed and mapped as early as 1862 , and had been thoroughly explored at least ten years before that date, without any of these gigantic birds being met with; but there is a large area of rugged mountainous country, especially in the south-west district of Otago, which even to the present time is only imperfectly known. The mountain sides in this region are clothed with open forest, in which Kiwis, Kakapos, and other expiring forms of apterous birds are still to be found in comparative abundance, but where we could scarcely expect to meet with the larger species. Nevertheless, owing to the lofty tabular configuration of this district, the mountains afford very extensive areas above the forest limit-which are covered with Alpine shrubs and grasses-where it is not impossible that a remnant of this giant race may have remained to very recent times. The exploration, however, to which the country has been subjected during the last few years, by parties of diggers prospecting for gold, forbids any reasonable hope that any still exist. I may here mention that on one of the flat-topped mountains near Jackson's Bay, visited in January 1863 , I observed, at an altitude of 4,000 feet, numerous well-beaten tracks about sixteen inches wide intersecting the dense scrub in all directions, and which, owing to the height of the scrub (two to four feet) could only been formed in the first instance by the frequent passage of a much larger bird than either the Kiwi or Kakapo, which, judging from the droppings, were the only birds that now resorted to them. On the sides of the tracks, especially near the upper confines of the forest, are shallow excavations, $2 \mathrm{ft}$. to $3 \mathrm{fc}$. in diameter, that have much the appearance of having been scraped for nests. No pigs or any other introduced animals having penetrated to this part of the country, it appears manifest that these were the tracks of some large indigenous animal, but from the nature of the vegetation it is probable that such tracks may have been for a very long period in disuse, except by the smaller ground birds, without becoming obliterated.

The above facts and arguments in support of the view that the Moa survived to very recent times, are similar to those advanced at an early period after the settlement of the colony, by Walter Mantell, who had the advantage of direct information on the subject from a generation of natives that has now passed away. As the first explurer of the artificial Moa beds, his opinion is entitled to great weight. Similar conclusions were also drawn by Butler, who is personally familiar with the facts derived from the North Islands, in an article which appeared in the Zoologist for 1864. The fresh discovery therefore of well-preserved remains of the Moa only tends to confirm and establish these views; and it would have been unnecessary to enlarge on the subject by the publication of the foregoing notes, which for the most part were written several years ago, but for the entirely opposite conclusions advanced by Dr. Haast in a recent address, which, from the large amount of interesting and novel matter it contains, will doubtless have a wide circisiation.

JAMES HECTOR

\section{ON THE GASEOUS AND LIQUID STATES OF}

\section{MATTER}

A DISCOURSE was delivered on Friday evening, June 2, at the Royal Institution in Albemarle Street, by Dr. Andrews on the "Gaseous and Liquid States of Matter," from which we make the following extracts:-"The liquid state of matter forms a link between the solid and gaseous states. This link is, however, often suppressed, and the solid passes directly into the gaseous or vaporous form. In the intense cold of an arctic winter, hard ice will gradually change into transparent vapour without previously assuming the form of water. Carbonic acid snow passes rapidly into gas when exposed to the air, and can with difficulty be liquefied in open tubes. Its boiling point, as Faraday has 
shown, presents the apparent anomaly of being lower in the thermometric scale than its melting point, a statement less paradoxical than it may at first appear, if we remember that water can exist as vapour at temperatures far lower than those at which it can exist as liquid. Whether the transition be directly from solid to gaseous, or from solid to liquid and from liquid to gaseous, a marked change of physical properties occurs at each step or break, and heat is absorbed, as was proved long ago by Black, without producing elevation of temperature. Many solids and liquids will for this reason maintain a low temperature, even when surrounded by a white hot atmosphere, and the remarkable experiment of solidifying water and even mercury on a red hot plate, finds thus an easy explanation. The term spheroidal state, when applied to water floating on a cushion of vapour over a red hot plate, is, however, apt to mislead. The water is not here in any peculiar state. It is simply water evaporating rapidly at a few degrees below its boiling point, and all its properties, even those of capillarity, are the properties of ordinary water at $9^{5^{\circ}}{ }_{5} \mathrm{C}$. The interesting phenomena

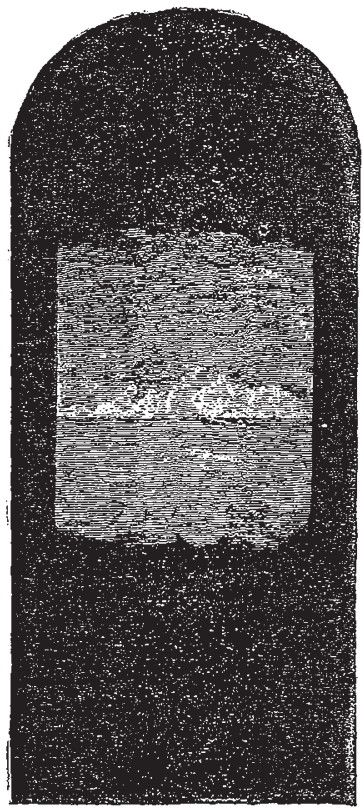

FIG. I-Cloud below critical point

peared. He afterwards succeeded in repeating the experiment in glass tubes, and arrived at the following results. An hermetically sealed glass tube, containing sufficient alcohol to occupy two-fifths of its capacity, was gradually heated, when the liquid was seen to dilate, and its molility at the same time to become gradually greater. After attaining to nearly twice its original volume, the liquid completely disappeared, and was converted into a vapour so transparent that the tube appeared to be quite empty. On allowing the tube to cool, a very thick cloud was formed, after which the liquid reappeared in its former state.

"It is singular that in this other wise accurate description Cagniard de la Tour should have overlooked the most remarkable phenomenon of all-the moving or flickering striæ which fill the tube, when, after heating it above the critical point, the temperature is quickly lowered. This phenomenon was first observed by the lecturer in 1863 , when experimenting with carbonic acid, and may be admirably seen by heating such liquids as ether or sulphurous acid in hermetically sealed tubes, of which when cold they occupy about one-third of the capacity. The exhibited under these conditions are due to other causes, and not to any new or peculiar state of the liquid itself. The fine researches of Dalton upon vapours, and the memorable discovery by Faraday of the liquefaction of gases by pressure alone, finished the work which Black had begun. Our knowledge of the conditions under which matter passes abruptly from the gaseous to the liquid and from the liquid to the solid state may now be regarded as almost complete.

"In 1822 Cagniard de la Tour made some remarkable experiments, which still bear his name, and which may be regarded as the starting point of the investigations which form the chief subject of this address. Cagniard de la Tour's first experiments ware made in a small Papin's digester constructed from the thick end of a gun barrel, into which he introduced a little alcohol and also a small quartz ball, and firmly closed the whole. On heating the gun barrel with its contents over an open fire, and observing from time to time the sound produced by the ball when the apparatus was shaken, he inferred that after a certain temperature was attained the liquid had disap-

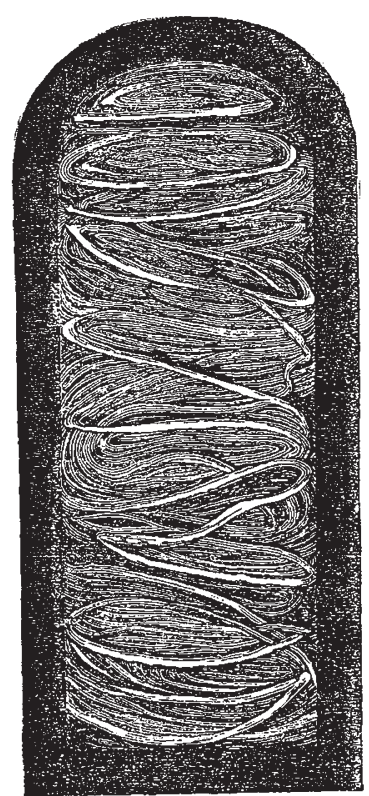

FIG. 2-Striz above critical point

appearances exhibited by the ascending and descending sheets of matter of unequal density are most remarkable, but it is difficult to give an adequate description of them in words or even to delineate them.

"These striz arise from the great changes of density which slight variations of temperature or pressure produce when liquids are heated in a confined space above the critical point already referred to; but they are not formed if the temperature and pressure are kept steady. When seen they are always a proof that the matter in the tube is homogeneous, and that we have not liquid and gas in presence of one another. They are, in short, an extraordinary development of the movements observed in ordinary liquids and gases when heated from below. The fact that at a temperature $0^{\circ} \cdot 2$ above its critical point carbonic acid diminishes to one-half its volume from an increase of only $\frac{1}{37}$ of the entire pressure is sufficient to account for the marked characters they exhibit.

"If the temperature is allowed to fall a little below the critical point, the formation of cloud shows that we hive now heterogeneous matter in the tube, minute drops of liquid in presence of a gas. From the midst of this cloud 
(as shown in Fig. 1) a faint surface of demarcation appears, constituting the boundary between liquid and gas, but at first wholly devoid of curvature. We must, however, take care not to suppose that a cloud necessarily precedes the formation of true liquid. If the pressure be sufficiently great, no cloud of any kind will form."

After describing the results obtained by the lecturer with carbonic acid under varied conditions of temperature and pressure, of which a full account has already appeared in NATURE, * Dr. Andrews remarked that it would be erroneous to say that between liquid and gas there exists one intermediate state of matter, but that it is correct to say that between ordinary liquid and ordinary gas there is an infinite number of intermediate conditions of matter, establishing perfect continuity between the two states. Under great pressures the passage from the liquid to the gaseous state is effected on the application of heat without any break or breach of continuity. A solid model, constructed by Prof. J. Thomson, from the data furnished by the experiments of the lecturer, exhibited very clearly the different paths which connect the liquid and gaseous states, showing the ordinary passage by break from the liquid, as well as the continuous passages above the critical point.

After referring to the experiments of Frankland on the change produced by pressure in the spectrum of hydrogen, and to those of the same able chemist and Lockyer on the spectrum of the spark in compressed gases, Dr. Andrews described the remarkable change from a translucent to an opaque body, which occurs when bromine is heated above the critical point; and then drew attention to the general fact that when the critical point is reached, the density of the liquid and gas become identical.

In order to establish the continuity of the solid and liquid states, it would be necessary in like manner, by the combined action of heat and pressure, to obtain the solid and liquid of the same density and of like physical properties. To accomplish this result would probably require pressures far beyond any which can be reached in transparent tubes, but future experiment may show that the solid and liquid can be made to approach to the required conditions.

\section{ON AN ADDITIONAL TRUE RIB IN THE HUMAN SUBҰECT}

$7 \mathrm{HE}$ almost absolute rule that there are seven true ribs in the human subject has, like every other rule, its exceptions. Occasionally instances are met with in which there are eight sternal ribs on one or both sides. But Nature does not effect her evolutions by per saltum transitions between extreme points, but steadily makes progress by degrees almost imperceptible to human intelligence. So in the matter of rib transition, there are various grades met with between the presence of a complete eighth sternal rib on the one hand, and its absence on the other. In the sternum of a female subject recently dissected at the Royal College of Surgeons, the right seventh and eighth rib cartilages blended together about a quarter of an inch distant from the mesosternum. On the left side the eighth rib cartilage was arrested about an inch and a half from the mesosternum. The latter was free at its sternal end. In another subject-a moderately muscular male-the eighth rib cartilage on the right side extended within an inch of the mesosternum, its extremity being free. On the left it was aborted at the distance of two and a half inches from the mesosternum. In the latter subject the sternum was exceedingly large; all the rib cartilages, especially the seventh on the left side, were well developed, and the xiphisternum was very much elongated, spatulate, and curved in an anterior direction. Occasionally specimens are met with in which the sixth rib cartilage is implanted upon the distal extremity of the mesosternum (rather than upon its distal lateral aspect), lying in front of the xiphisternum, and separated from its fellow of the opposite side by a small interval. In the receding angle formed by their divergence, the seventh sternal ribs are placed, lying directly upon the xiphisternum, and articulating with it, barely attaining an attachment to the mesosternum. This closely simulates the arrangement met with when the eighth sternal rib is present.

In another adult male skeleton, I found a complete specimen of an eighth sternal rib, but only on the right side. It articulated with the xiphisternum, and not with the mesosternum. On the left side the seventh sternal rib cartilage was larger than the corresponding one on the right side, and articulated with both the mesosternum and xiphisternum.*

On examining the skeletons (human) in the Hunterian Museum, I noticed another instance of an eighth sternal rib in an adult male African negro, occurring on the right side only. It was in every respect similar to the preceding. This is the only instance out of the fifteen skeletons (human) contained in the museum which deviated from the average standard number of seven true ribs. It is just possible that it may be more frequently present and remain undetected. In maceration the cartilages are very frequently removed, and articulators prepare artificial ones in their place corresponding to the average seven.

On examining the higher quadrumana, \&c., I noticed that this additional true rib was present only in one young chimpanzee, but not in the gorillas and orangs. It was present in the gibbon and silvery gibbon, the pig-tailed monkey, Macacus Rhesus, Galeopithecus, and Indri. The ayeaye, the slender lemur, and the squirrel monkey, have each nine true ribs. The grand galago, the awantilo, the slender loris, the douroucouli, and the potto, have each ten true ribs. Prof. Flower very kindly called my attention to a paper on the axial skeleton of the Primates by Mr. St. George Mivart, $\phi$ in which these rib variations are described as follows: - "In the highest forms of the Primates, the number of true ribs is seven, but in Hylobates there are sometimes eight pairs. In Semnopithecus and Colobus there are generally seven, but sometimes eight pairs of true ribs. In the Cynopithecinæ the normal number is eight. In the Cebidæ there are generally seven or eight pairs, but in Ateles sometimes nine. In Hapale there are sometimes as few as six, sometimes as many as eight; seven or eight in Galago, Lemur, and Indris; nine in Cheiromys. The highest number, as might be expected, is found in the Nycticebinæ, there being as many as ten pairs of true ribs in Perodicticus and Loris."

Professor Flower remarks " that "in the higher Simiina the ribs do not differ very notably from those of man, except in number; but in the lower forms, and especially in the Lemurina, they more resemble those of the Carnivora."

In the Carnivora the number of nine sternal ribs is fairly constant. There are some exceptions, however, e.g. the Esquimaux dog-the Arctic wolf and Proteles have only eight true ribs. The common badger (Meles taxus) has ten true ribs - the tenth rib being implanted on the apex of the xiphisternum. The ninth rib in all these animals is more or less intimately associated with the xiphisternum, but rarely forming so decided an articulation with it as in the badger.

In a dog's sternum lately in my possession, the xiphisternum had the ninth rib articulated directly with it.

* This does not obviate the rule laid cown by Prof. Flower in his recent admirable book on the Osteology of the Mammalia, that the xiphisternum never carries any true ribs. This is the average rule. But variations are frequent, although they cannot be considered in a text-book on average, and notirregular, Osteology.

$\dagger$ Proceedings of the Zoological Society of London June $27, \mathbf{1 8 6 5 .}$

+ Osteology of the Mammalia, p. 89 . 